\title{
Laser Texturing of Surfaces in Thin-Film Silicon Photovoltaics - A Comparison of Potential Processes
}

\author{
Tobias KNÜTTEL ${ }^{* 1,2}$, Stefan BERGFELD ${ }^{* 1}$ and Stefan HAAS ${ }^{* 2}$ \\ E-mail: t.knuettel@fz-juelich.de \\ ${ }^{*}$ 4JET Technologies GmbH, Konrad-Zuse-Straße 1, 52477 Alsdorf, Germany \\ ${ }^{* 2}$ Forschungszentrum Jülich GmbH, IEK5 -Photovoltaik, \\ Wilhelm-Johnen-Straße, 52425 Jülich, Germany
}

\begin{abstract}
Thin-film silicon solar cells contain textured interfaces in order to optimize light incoupling and light trapping. Laser-based texturing processes can offer a high degree of freedom concerning the adaptability of textures, therefore allowing controllable light management. In this article, four commonly known laser-based processes are adapted to texturing aluminium-doped zinc-oxide for the use as a front contact in thin-film silicon solar cells. They are compared considering the achievable textures as well as the industrial applicability of the process concerning scalability, throughput and simplicity. The patterning by the formation of laser induced periodical surface structures (LIPSS) proved to be a very simple way of achieving feature sizes on the right order of magnitude, whereas interference patterning offers a large variety of textures.
\end{abstract}

DOI: $10.2961 / \mathrm{jlmn} .2013 .03 .0007$

Keywords: thin-film, silicon, $\mathrm{ZnO}$ :Al, texture, LIPSS, interference, light management, solar cells

\section{Introduction}

Thin-film silicon (TFS) solar cells need textured interfaces. The textured interfaces help to reduce the reflection of incoming light by improving light incoupling. Furthermore, light absorption in the solar cell is enhanced by light scattering and light trapping. Feature sizes below the order of the wavelength of the incoming light improve light incoupling capacities, whereas larger features on the order of the wavelength improve light trapping [1-4] (Fig. 1).
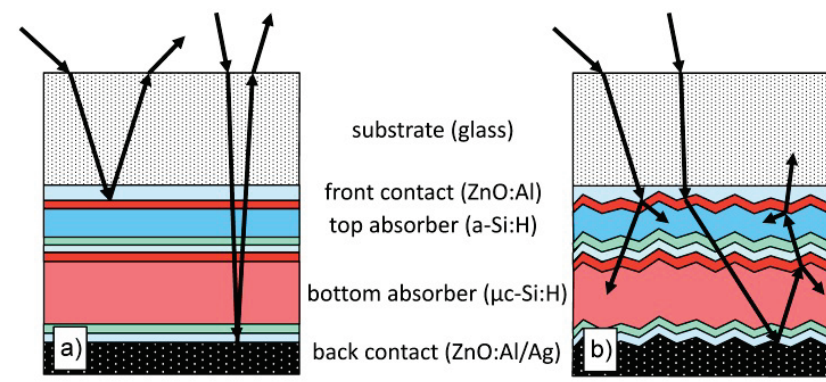

Fig. 1 Schematic drawing of light management in thinfilm silicon solar cells (a) with flat interfaces and (b) textured interfaces. Introducing textured interfaces improves cell efficiencies by refractive index matching (light incoupling - left ray in a) and b)) and by enhancing the light paths within the cell (light trapping - right ray in a) and b)).

The textured interfaces in the solar cell are usually introduced by texturing the front contact, a transparent and conductive oxide (TCO), here made of aluminum-doped zinc oxide ( $\mathrm{ZnO}: \mathrm{Al})$. Upon the textured $\mathrm{ZnO}$ :Al layer, all other layers are deposited in an almost conformal growth during the manufacturing process. Commonly, texturing of $\mathrm{ZnO}$ is done by wet chemical etching [2] or by an intrinsically textured growth of boron doped $\mathrm{ZnO}$ via low-pressure chemical-vapor-deposition (LPCVD) [5]. Whereas these processes are of industrial relevance and can be scaled to large areas, they only supply limited degree of freedom concerning the adaptability of the feature geometries and thus, the scattering properties of the texture.

Apart from these commonly used techniques, there are many ways $\mathrm{ZnO}: \mathrm{Al}$ can be textured in a laboratory environment in order to achieve a higher degree of freedom concerning the adaptability of the feature geometries. These processes range from texturing $\mathrm{ZnO}$ : Al by electrochemical etching [6] or photolithography [7] to texturing the glass substrate by nanoimprint lithography [8], [9], reactive ion etching [10] or ion beam etching [11]. However, all of these processes require a fairly complex experimental setup. The aim of this study is different because it focusses on the industrial feasibility in a cost effective environment.

Laser-processes for direct texturing of sputtered $\mathrm{ZnO}: \mathrm{Al}$ are a promising alternative to these existing methods. Textures produced by lasers generally reveal a high degree of freedom concerning shape and size of the features. Combined with the repeatable outcome of laser processes, this flexibility offers engineerable light management within the cell. Furthermore, most laser processes produce periodic textures, which are very well suited to further improve the light management [12-14]. Finally, most laser-processes are compliant with vacuum technology, allowing a faster and more energy efficient production without the need of vacuum breaks.

So far there have only been two studies focusing on direct laser patterning of $\mathrm{ZnO}$ :Al. Sämann et al [15] used a line source to cross-pattern sputtered films of $\mathrm{ZnO}: \mathrm{Al}$ in a direct writing process. The periodicities of the textures obtained are on the order of $10 \mathrm{um}$ and are suited for light trapping of infrared light, but are too large to trap shorter wavelengths, or to be used for light incoupling. 
Recently Eckhardt et al show promising results on laser-interference patterning of $\mathrm{ZnO}: \mathrm{Al}$. Line-like and hexagonal shaped patterns with a fixed periodicity of $1 \mu \mathrm{m}$ were created. [16]. Other, commonly known laser-based texturing processes have not been investigated for their applicability to texture $\mathrm{ZnO}: \mathrm{Al}$ for the use in thin-film silicon solar cells.

In this work, four commonly known techniques of laser processes were investigated and thoroughly compared also considering the industrial application of the processes. The techniques compared are (1) laser-induced chemical etching, (2) locally confined ablation by refocusing laser light with a particle lens array, (3) the formation of Laser Induced Periodical Surface Structures (LIPSS) as well as (4) locally confined ablation by laser-interference pattering.

Laser induced chemical etching offers a method to locally adapt the etching environment of the $\mathrm{ZnO}$ :Al. This is done by locally confined heating of the $\mathrm{ZnO}: \mathrm{Al}$ with laser light. The shape of the etch features as well as speed of the etch process strongly depend on temperature [4], a combination of etching with simultaneous laser illumination may allow a locally adaptable etch texture capable of a more adaptable light management within the cell.

A particle lens array deposited on the surface of a material and irradiated by laser light lead to a local intensity enhancement underneath the sphere [17-19]. The enhancement of the electromagnetic field can be used to texture the $\mathrm{ZnO}: \mathrm{Al}$ with small crater-like features.

LIPSS, also known as ripple structures, are surface textures typically on the order of the wavelength of the laser and below. They are mainly observed in multi-pulse processes of ultra-short-pulse lasers close to the ablationthreshold of the treated material. LIPSS have been investigated for decades and various theoretical descriptions exist [20-24]. Although there have been studies on LIPSS formation on $\mathrm{ZnO}$ [25-28], they are limited to the use of a scientific Ti:sapphire femtosecond laser with a wavelength of $800 \mathrm{~nm}$.

Laser interference patterning is a technique which uses the intensity pattern of coherent, overlapping laser beams to cover surfaces with periodic patterns [29]. To use interference patterning in the case of $\mathrm{ZnO}: \mathrm{Al}$, an ultraviolet (UV) laser in nanosecond regime is very suitable, because here the $\mathrm{ZnO}: \mathrm{Al}$ ablates nearly proportional to the intensity of the laser light [30]. Consequently, the intensity pattern of the interfering laser beams can be transferred to a topographical pattern on the surface of the $\mathrm{ZnO}: \mathrm{Al}$.

This article presents a broad, comparative study on the applicability of these laser-based processes for texturing $\mathrm{ZnO}: \mathrm{Al}$ in the manufacturing of TFS solar cells. The aim of this study is to pre-select industrial relevant processes concerning scalability, simplicity and adaptability of feature geometries.

\section{Methods}

\subsection{Laser-Induced Chemical Etching}

The laser-induced chemical etching was investigated in a reaction chamber built of polyether ether ketone (PEEK). The reaction chamber was filled with the acid and built into a laboratory laser system on a movable $\mathrm{x}, \mathrm{y}$ table allowing simultaneous etching and laser treatment. The substrate was used as a lid to the chamber so only the film side was in contact with the chemical. The laser illumination was carried out from the glass side. To install the chamber into the laser system, do the laser treatment, and remove it, at least 20 min working time were needed. Therefore, in order to avoid a complete removal of the $\mathrm{ZnO}: \mathrm{Al}$ film, the use of $\mathrm{HCl}$ was limited to weak concentrations. To further slowdown the etching process the reaction chamber as well as the acid was cooled to $13{ }^{\circ} \mathrm{C}$. Hence, $\mathrm{HCl}$ with a concentration of $1 \cdot 10^{-2} \mathrm{w} / \mathrm{w} \%$ could be used without destroying the film. A Nd: $\mathrm{YVO}_{4}$ laser with a wavelength of $1064 \mathrm{~nm}$ was used in cw- as well as in pulsed-mode. Due to the rather low absorption at $1064 \mathrm{~nm}$ the $\mathrm{ZnO}$ : Al was heated almost homogenous in growth direction. In pulsed mode with a pulse length of $10 \mathrm{~ns}$ to $20 \mathrm{~ns}$, fluences up to $30 \mathrm{~J} / \mathrm{cm}^{2}$ could be realized. In continuous wave mode, power densities up to $25 \mathrm{~kW} / \mathrm{cm}^{2}$ were applied.

\subsection{Refocusing by Particle Lens Array}

For the particle lens array, commercially available (Corpuscular Inc) silica spheres with a diameter of $450 \mathrm{~nm}$ were used. The spheres were dissolved in water and applied to the $\mathrm{ZnO}$ :Al film by drop coating. For the drop coating, volume concentrations ranging from $1 \cdot 10^{-4} \mathrm{~m}^{3} / \mathrm{m}^{3}$ to $5 \cdot 10^{-2} \mathrm{~m}^{3} / \mathrm{m}^{3}$ were used. In small, partial areas of the sample, a perfect monolayer of touching spheres could be achieved. After drying, the substrate was placed on an $\mathrm{x}, \mathrm{y}$ table. Three different $\mathrm{Nd}: \mathrm{YVO}_{4}$ lasers with pulse durations of $10 \mathrm{~ns}$ to $20 \mathrm{~ns}$ were available for the treatments. The wavelengths of the lasers were $1064 \mathrm{~nm}, 532 \mathrm{~nm}$, and $355 \mathrm{~nm}$, the focal radii $50 \mu \mathrm{m}, 60 \mu \mathrm{m}$ and $19 \mu \mathrm{m}$ and fluences measured in front of the particle lens array of up to $30 \mathrm{~J} / \mathrm{cm}^{2}, 7 \mathrm{~J} / \mathrm{cm}^{2}$, and $5 \mathrm{~J} / \mathrm{cm}^{2}$ respectively. Repetition rates were varied from 10 to $20 \mathrm{kHz}$. Because almost all particles were removed by the laser irradiation, no cleaning step was needed after the laser treatment.

\subsection{LIPSS Formation}

In order to obtain LIPSS with different spatial periodicities, two picosecond Yb:YAG lasers with wavelengths of $1030 \mathrm{~nm}$ and $515 \mathrm{~nm}$ and pulse durations of $10 \mathrm{ps}$ were used. The polarization of the laser beam was controlled by quarter and/or half-wave plates to obtain circular polarized as well as linear polarized light of any angle. The beam was deflected by a galvo scanner system and focussed on the film side of the substrate under normal incidence. Telecentric lenses of various focal lengths focused the beam, yielding fluences up to $5 \mathrm{~J} / \mathrm{cm}^{2}$ and $18 \mathrm{~J} / \mathrm{cm}^{2}$ for $1030 \mathrm{~nm}$ and $515 \mathrm{~nm}$ respectively.

\subsection{Interference Patterning}

In Figure 2 a schematic drawing of the two-beam interference setup is depicted. A frequency tripled Nd:YAG Laser with a wavelength of $355 \mathrm{~nm}$ and a pulse duration of $7 \mathrm{~ns}$ was used. The laser beam was split using a polarizing beam splitter cube and reunited at the substrate at an adjustable angle to the surface. The substrate was mounted vertically on a $\mathrm{x}, \mathrm{y}, \mathrm{z}$ positioning system. The intensities of the partial beams were equalized by a quarter-wave plate in 
front of the beam-splitter cube and their polarization was aligned by two half-wave plates in each partial beam path. Without focusing, fluences of up to $9 \mathrm{~J} / \mathrm{cm}^{2}$ could be reached.

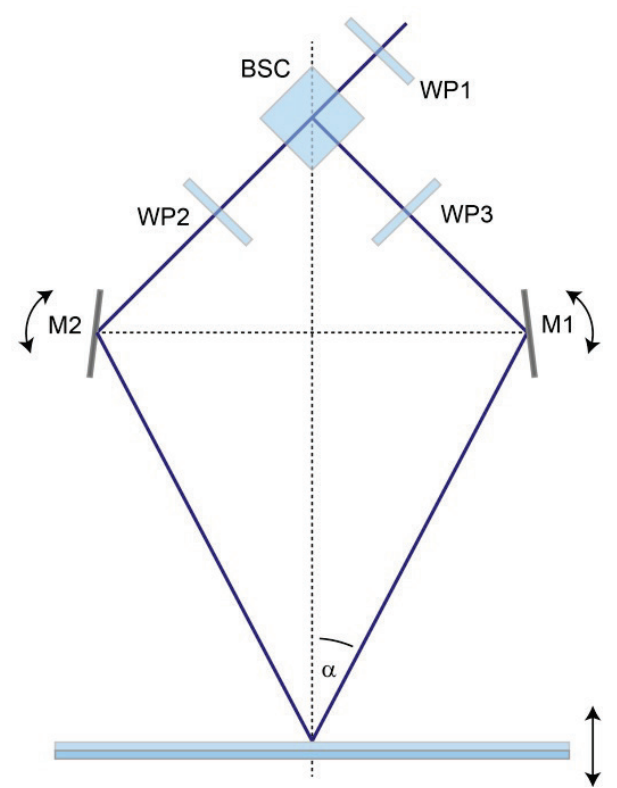

Fig. 2 Experimental setup for two-beam-interference patterning. A linear polarized UV nanosecond laser was split by a polarizing beam splitter cube (BSC), wheras the polarizations of the partial beams could be aligned by half-wave plates (WP2, WP3). The beam was reunited at the sample under the angle of incidence $\alpha$ by two adjustable mirrors (M1, M2). The intensities of the partial beams could be adjusted by a half-wave plate (WP1).

\subsection{Characterization}

For the calculation of fluences, spot sizes are needed which were determined by a method proposed by Liu [31]. Pulse energies as well as laser powers were determined with commercially available equipment. Topographical characterization of the textures was conducted with a SIS Nanostation 300 atomic force microscope (AFM), a Zeiss Evo MA10 scanning electron microscope (SEM) and optical microscopes. Optical measurements of scattering properties were carried out with a PerkinElmer Lambda 950 spectrometer with integrating sphere. Scattering properties were measured at the interface $\mathrm{ZnO}: \mathrm{Al}$ and air. Light scattered in angles larger than $\pm 5^{\circ}$ was considered to be scattered diffusely. The haze value was calculated by dividing diffuse transmission by total transmission. The substrate used for all experiments was a $1.1 \mathrm{~mm}$ thick $10 \times 10 \mathrm{~cm}^{2}$ corning glass with a radio frequency sputtered layer of $\mathrm{ZnO}: \mathrm{Al}$ on one side [2]. The layer thickness before the laser treatment was approximately $750 \mathrm{~nm}$.

\section{Results}

\subsection{Laser-Induced Chemical Etching}

The treatment by laser-induced etching in general revealed comparable textures as etching without laser treatment. The surface texture as well as the etch rate were not significantly influenced by heat induction by the laser.
Pulsed, as well as continuous laser light were used for the experiment. Very slow feed rates of down to $0.1 \mathrm{~mm} / \mathrm{s}$ were applied in order to obtain the highest possible heat intake in the reaction volume. In case of the pulsed processes, the ablation threshold of the $\mathrm{ZnO}: \mathrm{Al}$ film was determined to be at $0.8 \mathrm{~J} / \mathrm{cm}^{2}$ (at feed rate of $0.1 \mathrm{~mm} / \mathrm{s}$, repetition rate of 10 $\mathrm{kHz}$ and beam spot radius of $50 \mu \mathrm{m}$ ). Above this fluence, the film was removed completely. Closely underneath the ablation threshold at approximately $0.77 \mathrm{~J} / \mathrm{cm}^{2}$ no significant differences in the texture could be measured. Also the use of cw-mode did not reveal any significant effect on the treated areas. Powers less than $850 \mathrm{~mW}$ did not show any effect, whereas higher powers led to crack formation and complete ablation of the material. For comparison, two textures of a purely etched and an etched and simultaneously laser-treated area of the same sample are depicted in Figures 3a) and b).

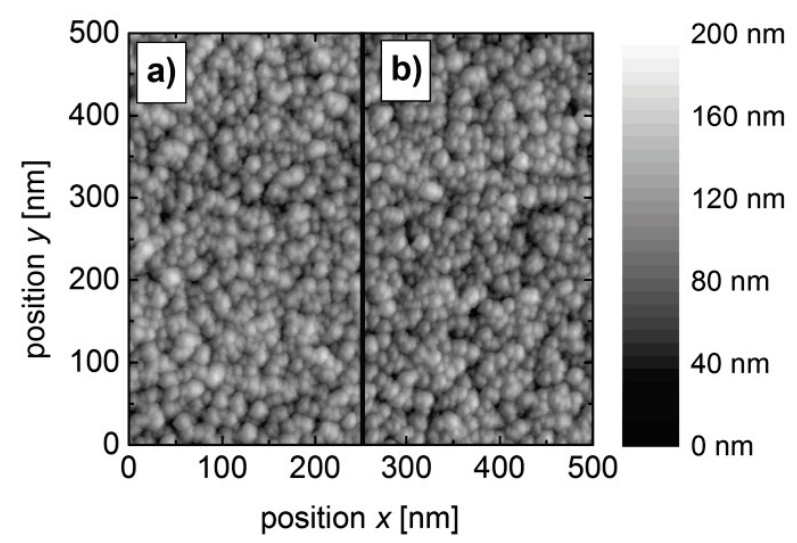

Fig. 3 AFM images of two different areas of the same sample. (a) The sample was submerged in $1 \cdot 10^{-2}$ $\mathrm{w} / \mathrm{w} \% \mathrm{HCl}$ at $13{ }^{\circ} \mathrm{C}$ for $20 \mathrm{~min}$. (b) Additionally, a nanosecond infrared laser with a fluence of $0.77 \mathrm{~J} / \mathrm{cm}^{2}$ was scanned over the sample at $0.1 \mathrm{~mm} / \mathrm{s}$. The measurements show no significant difference in the textures.

\subsection{Refocusing by Particle Lens Array}

By refocusing the laser beam with a particle lens array, crater-like structures could be obtained. Using the UV laser with fluences from $0.19 \mathrm{~J} / \mathrm{cm}^{2}$ to $0.23 \mathrm{~J} / \mathrm{cm}^{2}$, a pattering of microscopic areas with single craters was possible. Lower fluences merely removed the spheres from the surface without any pattering, whereas higher fluences led to a melting process and unification of more small craters to unwanted, larger features ("unified craters"). Above 0.68 $\mathrm{J} / \mathrm{cm}^{2}$, flake formation was observed and the $\mathrm{ZnO}: \mathrm{Al}$ could be assumed to be damaged. The diameters of the single craters range from $300 \mathrm{~nm}$ to $800 \mathrm{~nm}$. On average, the craters are approximately $50 \mathrm{~nm}$ deep, whereas there were strong deviations. Depths of up to $200 \mathrm{~nm}$ also occured.

An exemplary texture created with $0.22 \mathrm{~J} / \mathrm{cm}^{2}$ and a spatial overlap of the laser focal diameter of $47 \%$ is depicted in Figure 4 a) to c). The UV Laser was used with a repetition rate of $15 \mathrm{kHz}$ and a power of $38 \mathrm{~mW}$. In this texture all three processes can be observed; single craters (Fig. $4 \mathrm{~b}$ and 2 in Fig. 4a), larger features of melted unified craters (Fig. 4c and 3 in Fig. 4a)) and un-textured areas because of removal of the spheres ( 1 in Fig. 4 a). Due to 
the high sensitivity to fluences, covering larger areas was challenging. The flanks of the Gaussian beam spot removed the spheres from the surface because the fluence was not high enough to ablate the $\mathrm{ZnO}: \mathrm{Al}$, but sufficed to remove the spheres (1 in Fig. 4a)). This led to an un-textured area around the beam spot which then could not be textured by the next pulse. However, using the same overlap and higher fluences led to larger areas of unified craters in the center of the spots ( 3 in Fig. 4a)). Consequently, seamless stitching of Gaussian pulses and covering larger areas with the texture was not possible.

Using the infrared laser, no crater-like texture could be obtained. For fluences up to $0.4 \mathrm{~J} / \mathrm{cm}^{2}$ the $\mathrm{ZnO}$ : $\mathrm{Al}$ remained untouched, whereas for higer fluences cracks occurred.

With the green laser, a similar texture as in Figure 4 a) to c) could be obtained. However, the process window was even smaller compared to processing with the UV laser and higher fluences of $3.5 \mathrm{~J} / \mathrm{cm}^{2}$ were needed.

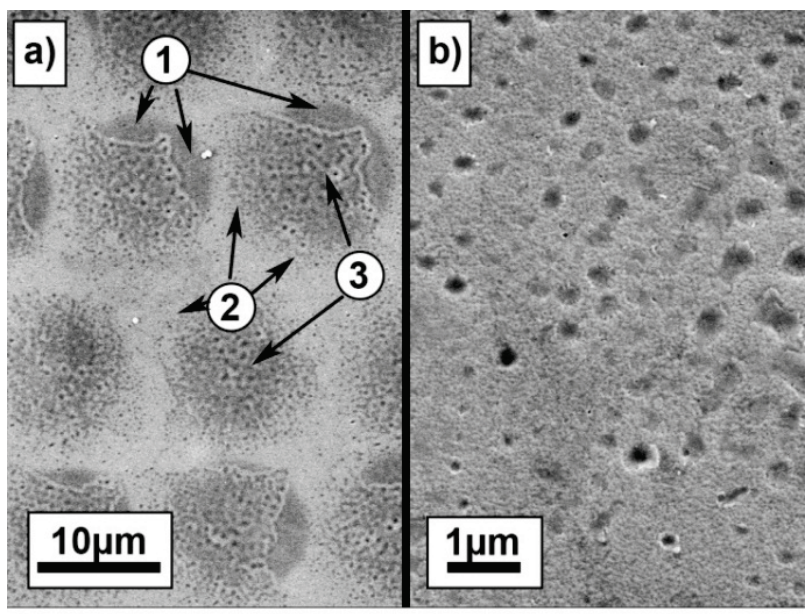

C)

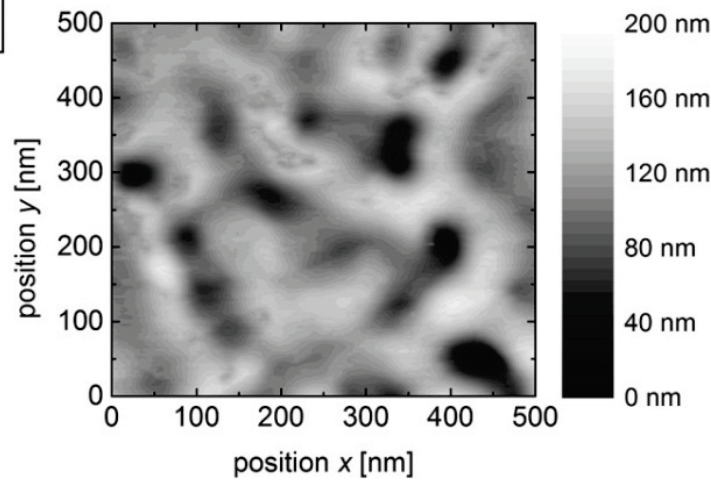

Fig. 4 Exemplary texture obtained with particle lens array using a fluence of $0.22 \mathrm{~J} / \mathrm{cm}^{2}$ and a spatial overlap of $47 \%$. (a) The SEM image shows an overview of the patterned area containing three different processes: low fluences on the perimeter of the spots led to the removal of spheres and left untextured areas (1), medium fluences closer to the center of the spots led to a single crater texture (2), high fluences in the spot centers led to a fusion of craters to larger features (3). (b) SEM image of single crater texture (as in (2)). (c) AFM image of spot center (as in (3)).

\subsection{LIPSS Formation}

Using the infrared laser with linear polarized light, Low Spatial Frequency LIPSS (LSFL) could be created. The process windows ranged from $0.53 \mathrm{~J} / \mathrm{cm}^{2}$ to $0.61 \mathrm{~J} / \mathrm{cm}^{2}$ with a spatial pulse overlap of at least $80 \%$. Using lower fluences did not yield any effect on the $\mathrm{ZnO}: \mathrm{Al}$, whereas higher fluences led to flake formation and partial ablation of the $\mathrm{ZnO}: \mathrm{Al}$ destroying the electrical properties of the film. Within the process window, the texture shows a clearly periodic ripple structure with a periodicity of approximately $900 \mathrm{~nm}$ and a groove depth ranging from $200 \mathrm{~nm}$ to $300 \mathrm{~nm}$. It was possible to rotate the orientation of the grooves by changing the angle of the linear polarization. However, it was not possible to texture the same area twice with different LIPSS orientations as to obtain a cross hatched texture. Only the geometry of the second treatment remained.

An exemplary texture created with a fluence of $0.53 \mathrm{~J} / \mathrm{cm}^{2}$ and an overlap of $88 \%$ is depicted in Figures $5 a)$ to c). Up scaling to larger areas $\left(10 \times 10 \mathrm{~cm}^{2}\right)$ was possible with only little stitching effects (Fig. 5a).

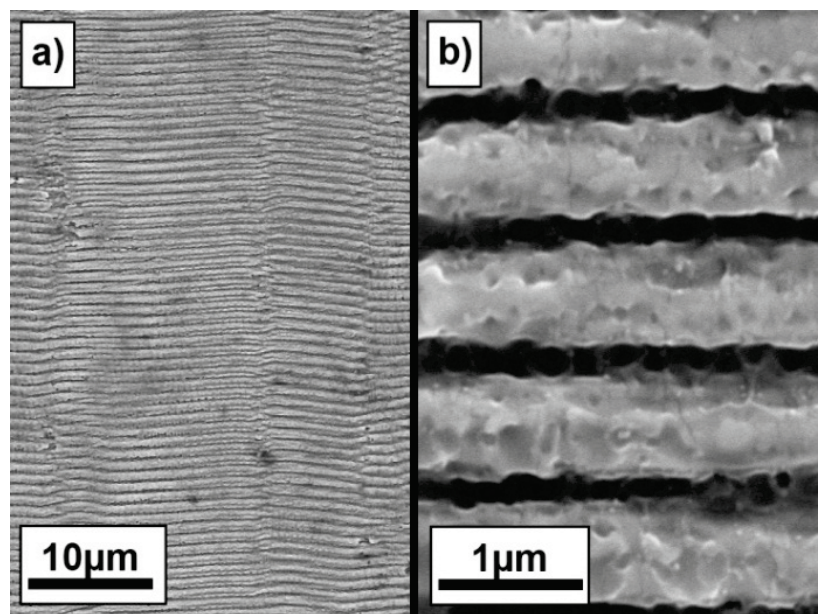

c)

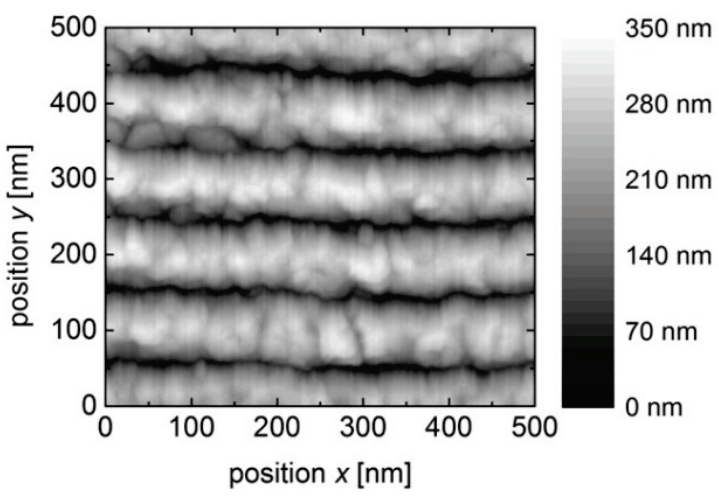

Fig. 5 Exemplary LSFL texture obtained with a linearly polarized, infrared picosecond laser using a fluence of $0.53 \mathrm{~J} / \mathrm{cm}^{2}$ and a spatial pulse overlap of $88 \%$. (a) SEM image of larger area with visible stitching effects. (b) SEM image of feature geometry in detail. (c) AFM image of topography. The texture is of clear periodic character with a periodicity of $900 \mathrm{~nm}$ and a groove depth of $300 \mathrm{~nm}$.

Using the green laser with circular polarized light, a coral-like texture with small features could be created. The fairly narrow process window ranged from $0.68 \mathrm{~J} / \mathrm{cm}^{2}$ to $0.75 \mathrm{~J} / \mathrm{cm}^{2}$ with spatial overlaps from $80 \%$ to $85 \%$. For 
higher fluences or overlaps, there was a strong crack formation, whereas for lower fluences or smaller overlaps, there was no LIPSS formation and the $\mathrm{ZnO}$ : $\mathrm{Al}$ remains untextured. The feature sizes of the textures range from $200 \mathrm{~nm}$ to $350 \mathrm{~nm}$. Using linear polarized light, some of the features could be aligned according to the polarization. However, it was not possible to obtain a clearly periodic line-like texture. For reasons of simplicity and due to the correlation with the LSFL process regarding polarization dependency and process parameters, the process is referred to as a HSFL process - albeit the periodicity not being very obvious.

An exemplary texture is depicted in Figures 6 a) to c). It was induced with circular polarized light, a fluence of $0.73 \mathrm{~J} / \mathrm{cm}^{2}$ and a pulse overlap of $83 \%$. A root-meansquare (rms) roughness of approximately $100 \mathrm{~nm}$ was calculated from AFM measurements (Fig. 4c). Applying the texture to larger areas $\left(10 \times 10 \mathrm{~cm}^{2}\right)$ was possible with almost no stitching effects (Fig. 6a).
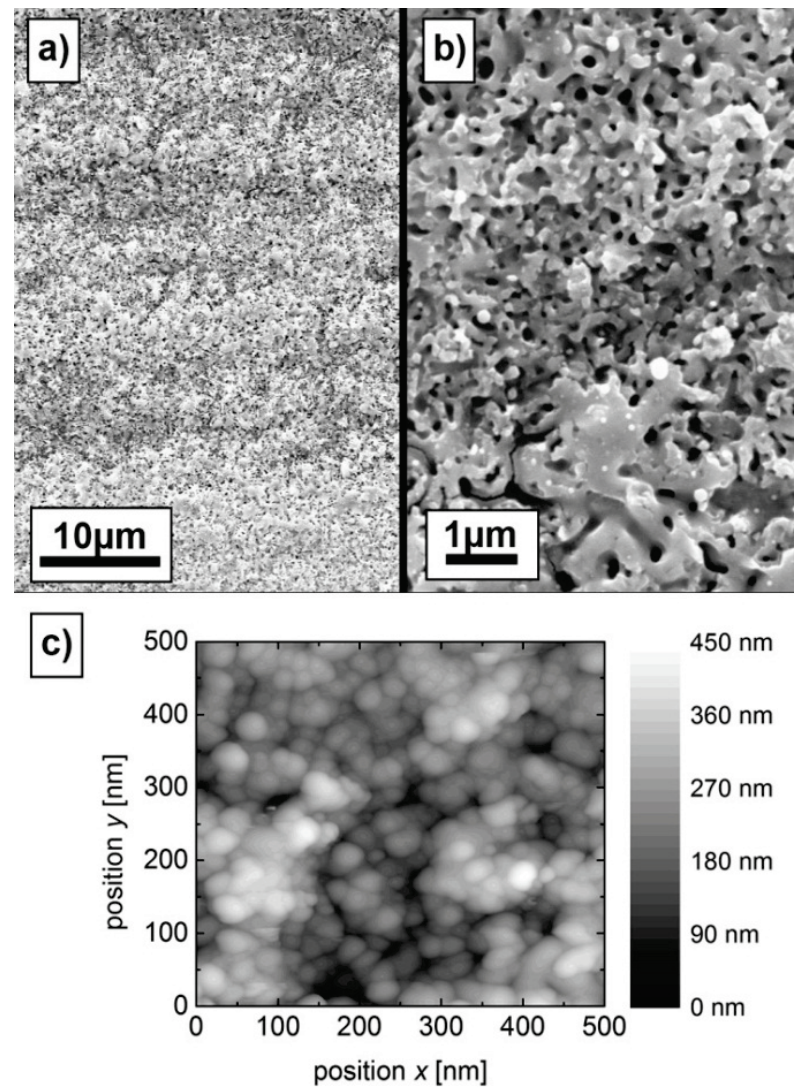

Fig. 6 Exemplary HSFL texture obtained with a circular polarized, green picosecond laser using a fluence of $0.73 \mathrm{~J} / \mathrm{cm}^{2}$ and a pulse overlap of $83 \%$. (a) SEM image of larger area. (b) SEM image of feature geometry in detail. (c) AFM image of topography. The feature sizes of the texture range from $200 \mathrm{~nm}$ to $350 \mathrm{~nm}$ with a rms roughness of $100 \mathrm{~nm}$.

\subsection{Interference Patterning}

Using interference patterning, we were able to produce various, strictly periodic textures in $\mathrm{ZnO}$ : $\mathrm{Al}$. With a single shot treatment, areas of approximately $2 \mathrm{~mm}^{2}$ could be covered with a line-like texture. The periodicities of the textures could be continuously adjusted from $400 \mathrm{~nm}$ to $1500 \mathrm{~nm}$. As the intensity distribution within the laser spot was very inhomogeneous and the power fluctuations of the laser system ranged up to $20 \%$, the calculated fluences underlay strong variations and have to be treated with caution. However, some general trends could be observed. For lower fluences the $\mathrm{ZnO}$ : Al was only ablated at the peak intensities of the interference pattern, while in between a flat, un-treated area remained. With rising fluences, the groove depth rose until the $\mathrm{ZnO}: \mathrm{Al}$ was ablated even in between the peak intensities, leading to a sine-like texture. In some areas, formation of small cracks could also be observed. For even higher fluences the $\mathrm{ZnO}: \mathrm{Al}$ film was completely ablated at the peak intensities.

An exemplary line-like texture is shown in Figure 7a) to c). It was created with an angle of incidence ( $\alpha$ in Fig. 2$)$ of $6.8^{\circ}$ and a pulse energy of approximately $30 \mathrm{~mJ}$. Referring to the textured area, this yields a fluence of approximately $1.5 \mathrm{~J} / \mathrm{cm}^{2}$. The texture is of clear periodic character, with a periodicity of $1.5 \mu \mathrm{m}$ and a groove depth of approx. $500 \mathrm{~nm}$ (Fig. 7c). In areas with high fluences, there also was a formation of small cracks (Fig. 7b).
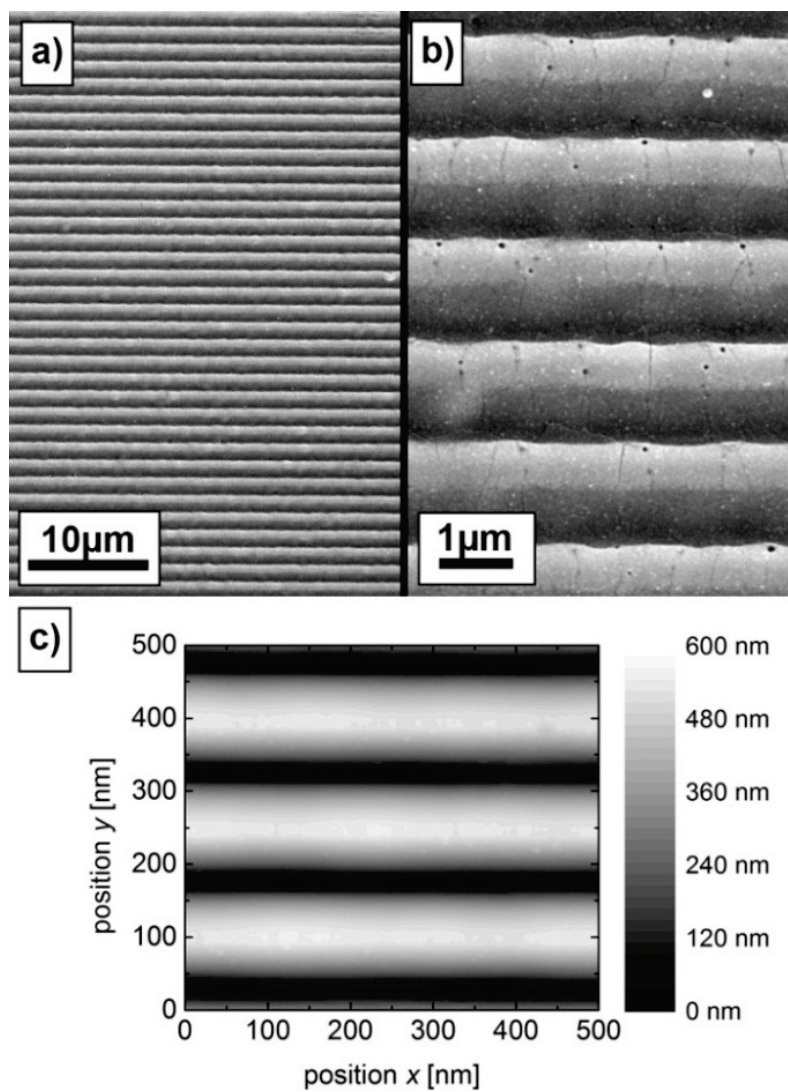

Fig. 7 Exemplary texture obtained by two-beaminterference patterning with an angle of incidence of $6.8^{\circ}$ and using a fluence of approx. $1.5 \mathrm{~J} / \mathrm{cm}^{2}$. (a) SEM image showing overview, (b) SEM image showing detailed feature and some crack formation, (c) AFM image of topography. The smooth texture was of very periodic character with a periodicity of $1.5 \mu \mathrm{m}$ and a groove depth of $500 \mathrm{~nm}$

An example of texture periodicities of $1200 \mathrm{~nm}$, $1000 \mathrm{~nm}$ and $800 \mathrm{~nm}$ can be observed in Fig. 8a). The according angle of incidence was $8.5^{\circ}, 10.2^{\circ}, 12.8^{\circ}$ respectively. In order to obtain two-dimensional textures, two processes creating line-like textures could be superposed 
with a rotation of the substrate in between the treatments. An exemplary two-dimensional structure with a sample rotation of $45^{\circ}$ is shown in Fig. $8 b$ ).
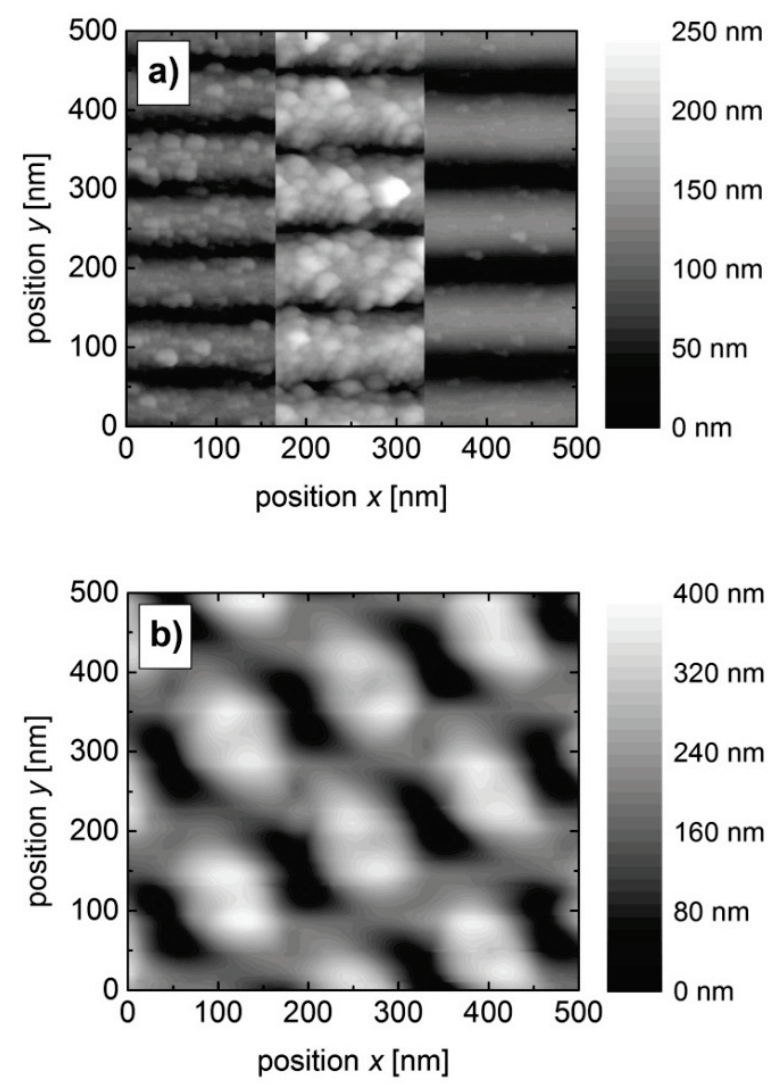

Fig. 8 Various textures obtained by laser interference patterning. (a) AFM image of three textures obtained with a fluence of approx. $2 \mathrm{~J} / \mathrm{cm}^{2}$ and angles of incidence of $8.5^{\circ}$ (left), $10.2^{\circ}$ (middle) and $12.8^{\circ}$ (right). The dot-like texture overlaying the periodic grooves is assumed to be ablated $\mathrm{ZnO}: \mathrm{Al}$ resettling on the film. (b) AFM image of texture obtained by superposing two line-like textures. The sample was textured with the same parameters as in Fig. 7, rotated for $45^{\circ}$ and processed again with the same parameters.

A detailed look at the height profile of the texture depicted in Fig. 7 c) reveals a sine-like texture. Comparing the measured height profile of the surface with the calculated (according to [32]) intensity profile within the overlapping region of the beams, there is a good match (Fig. 9). This underlines the fact that the $\mathrm{ZnO}$ :Al ablated proportional to the laser intensity and yields an easily predictable and calculable geometric shape of the texture.

Due to the very inhomogeneous beam profile of the laser beam used for the experiment, homogeneous texturing of large areas was not possible. However, the difficulties mainly were an experimental issue and can probably be solved by a better suited beam profile.

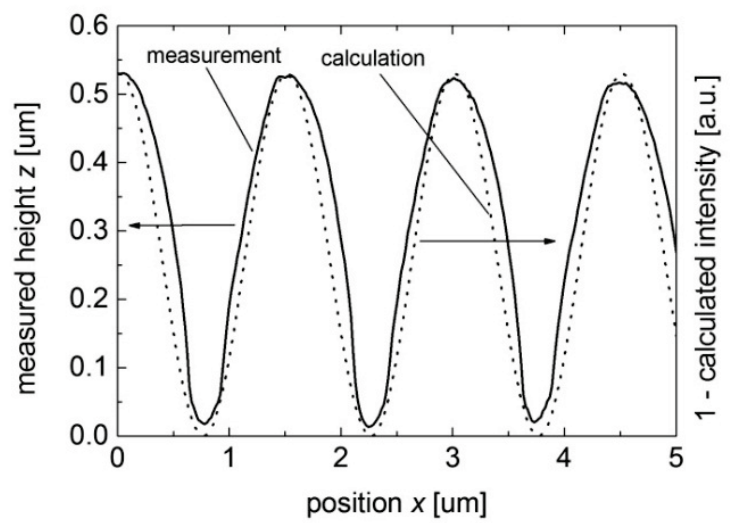

Fig. 9 Comparison of measured height profile and calculated intensity of two interfering waves. The measurement data is identical to the data presented in Fig. $7 \mathrm{c}$ ). The intensity was calculated according to [34] assuming parallel polarization and was scaled vertically to fit the measurement. The good match of measurement and calculation offers an analytical description of possible textures which permits integration with optical simulations.

\section{Discussion}

The process for texturing the $\mathrm{ZnO}$ : $\mathrm{Al}$ has to meet many requirements. It needs to be capable of producing textures with feature sizes in the sub-micrometer range. Furthermore, the geometries and sizes of these features need to be adjustable so scattering properties can be controlled. In addition to these physical requirements on the outcome of the texturing process, the process itself needs to meet technological requirements for industrial applicability. It needs to be simple and scalable to large areas, in order to be compliant with the cost, material and energy effective manufacturing of TFS solar cells. A simplified summary of the comparison of the four processes investigated in this article with regard to these main demands is depicted in Table 1.

The laser induced etching with $\mathrm{HCl}$ did not reveal a significant altering of the texture when compared with solely etched $\mathrm{ZnO}$ :Al. Within the possibilities of the given experimental setup, it was not possible to control the etch process by laser illumination. For high fluences, the $\mathrm{ZnO}$ :Al film was damaged, whereas for lower fluences no significant difference in texture could be measured. Albeit requiring a somewhat complex setup, the process isapplicable to large areas in an industrial environment.

Refocusing the laser with a particle lens array was capable of producing crater-like textures. Whereas the diameters of the craters are on the right order of magnitude, the average depth of only $50 \mathrm{~nm}$ is too shallow for effective light scattering. Furthermore, seamless stitching of Gaussian pulses to large areas was not possible due to the high

Table 1 Summarized findings of the comparison of processes.

\begin{tabular}{ccccc}
\hline Process & Feature Sizes & Flexibility & Scalability & Simplicity \\
\hline Laser-Induced Etching & - & - & 0 & 0 \\
Particle Lens Array & 0 & 0 & - & - \\
LIPSS Formation & + & 0 & + & + \\
Interference Patterning & + & + & 0 & 0 \\
\hline
\end{tabular}


fluence sensitivity of the process. It has to be investigated if a top-hat beam profile could overcome this problem. Finally, the deposition of a homogeneous monolayer of lenses on larger areas by simple deposition methods was challenging. Although it has been demonstrated that perfect monolayers of such spheres can be deposited [17], [33], the deposition of such a monolayer by simple and cost effective methods like drop coating could not be achieved.

More complex deposition methods like spin coating, however, are not applicable to larger scales in a cost effective production environment.

The formation of LIPSS with ultra-short-pulse lasers was the most simple process investigated that is capable of producing usable textures. The experimental setup merely consisted of a device to scan the focused laser over the substrate. The covering of large areas was possible with only little stitching effects and the needed fluences promise a covering of square meters in less than minute's time. The feature sizes of the two textures created are well suited for light trapping $(900 \mathrm{~nm})$ and light incoupling (200 $\mathrm{nm}$ to $300 \mathrm{~nm}$ ). The drawbacks of the technology are a fairly small processing window, challenging growth of silicon on the very porous textures and limited flexibility. Whereas the periodicity of the texture could be adjusted by the wavelength of the laser and the angle of incidence [25], so far it was not possible to choose arbitrary periodicities. Furthermore, the variety of achievable feature shapes was very limited.

Concerning flexibility and adaptability, the processing by laser interference patterning is peerless. Feature-sizes can be continuously adjusted by the angles and polarizations of the interfering beams. Given the restrains of the texture by the experimental setup, optical modeling software can optimize the texture in order to improve light management for the solar cell. The modeled texture can then easily be realized experimentally by adjusting the interference-setup accordingly. The textures created could be superposed, so two dimensional textures were realized with a fairly simple setup. By expanding the setup to threebeam-interference, even more complex two dimensional textures can be created with one shot [29]. Apart from the slightly more complex experimental setup, the main drawback of the experimental setup used for this study was scalability. Whereas the fluences probably can be lowered to allow speed-effective covering of large areas, the inhomogeneous beam profile prevented a homogeneous patterning of macroscopic areas. However, the difficulties in macroscopic patterning mainly were an experimental issue due to the misshapen beam profile of the laser beam used and not of the technique itself. It has to be determined if other lasers, e.g. with top-hat profile are more suitable.

To provide an outlook on the scattering properties of the various textures, the haze of each of the presented textures is plotted in Fig. 10. The plotted curves are measurements of exemplary textures only and do no not represent the overall potential of a given process. A high haze does not necessarily correlate with good light management [35]. The results are presented to prove that the chosen textures show scattering properties and have the potential to be used for light management. It will be the task of future studies to optimize the textures for effective light management in thin-film silicon solar cells.

Another ambitious task will be the growth of thin-film silicon layers on these optimized textures. The various layers of thin-film silicon need to have good optical and electrical properties in order to achieve high efficiency solar cells. Likewise, the growth of the layers needs to be welldefined and predictable in order to be able to control the textures of the various interfaces. Depending on the texture, the growth of such layers can be challenging [36-38].

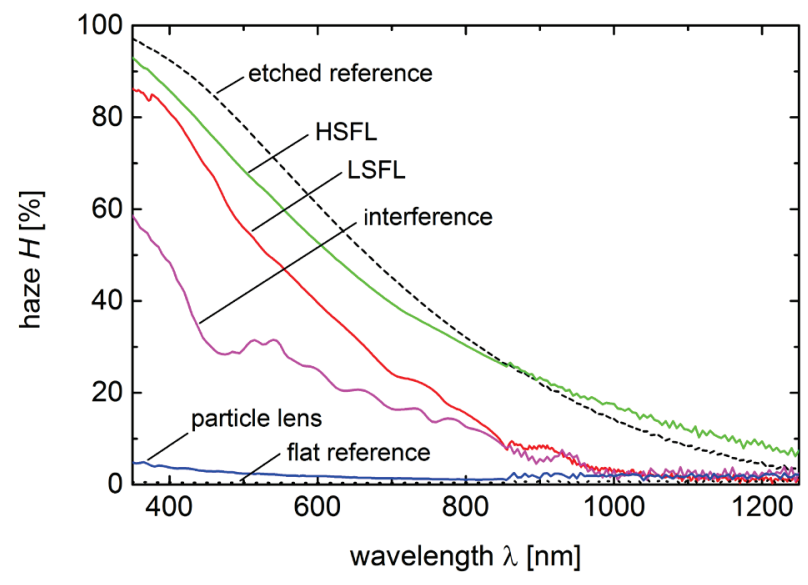

Fig. 10 Scattering properties for the textures presented in Fig. 4-6 and 8a) (middle). All textures reveal a higher haze value (diffuse divided by total transmission) than the untreated, flat $\mathrm{ZnO}: \mathrm{Al}$ (dotted line). The measurements of these exemplary textures do not represent the overall potential of each technique, but show that the scattering properties are improved compared to the untreated sample. The dashed line represents a sample treated with the standard wet-chemical etching process as described in [2].

\section{Conclusion}

Given the requirements of an industrially feasible process that is able to produce adaptable textures with featuresizes in the sub-micrometer range, two capable techniques could be established.

On the one hand, multi-beam-interference patterning of $\mathrm{ZnO}$ :Al captivates because of its great flexibility and predictability which permits good integration with optical modeling. One and two dimensional periodic patterns of various sizes and shapes were created. On the other hand, the formation of LIPSS merely required a very simple setup to achieve textures on the right order of magnitude. Covering of large areas was possible without severe stitching effects.

It is now the task of future studies to further refine these two techniques, investigate combinations of processes and adapt the scattering properties of the textures to the exact needs of thin-film silicon solar cells.

\section{Acknowledgements}

The authors would like to thank U. Rau and J. Hüpkes for productive discussions, G. Schöpe, T. Melle and K. Haesser for technical assistance, and the state of North Rhine-Westphalia as well as the European Union for financial funding (Project "LATEXT" EN3003/B). 


\section{References}

[1] K. Ding, T. Kirchartz, B. E. Pieters, C. Ulbrich, A. M. Ermes, S. Schicho, A. Lambertz, R. Carius, and U. Rau: Solar Energy Materials and Solar Cells, vol. 95, no. 12 , (2011), pp. 3318-3327

[2] M. Berginski, J. Hüpkes, M. Schulte, G. Schöpe, H. Stiebig, B. Rech, and M. Wuttig: Journal of Applied Physics, vol. 101, no. 7, (2007), p. 074903

[3] J. Müller, B. Rech, J. Springer, and M. Vanecek: Solar Energy, vol. 77, no. 6, (2004), pp. 917-930

[4] J. I. Owen, S. E. Pust, E. Bunte, J. Hüpkes, E. C. S. J. Solid, S. Sci, and P. P-p: ECS Journal of Solid State Science and Technology, vol. 1, no. 1, (2012), pp. 1017

[5] S. Faÿ, J. Steinhauser, S. Nicolay, and C. Ballif: Thin Solid Films, vol. 518, no. 11, (2010), pp. 29612966

[6] S. E. Pust, J.-P. Becker, J. Worbs, S. O. Klemm, K. J. J. Mayrhofer, and J. Hüpkes: Journal of The Electrochemical Society, vol. 158, no. 7, (2011), p. D413

[7] C. Eisele, C. E. Nebel, and M. Stutzmann: Journal of Applied Physics, vol. 89, no. 12, (2001), p. 7722

[8] C. Battaglia, J. Escarré, K. Söderström, M. Charrière, M. Despeisse, F.-J. Haug, and C. Ballif: Nature Photonics, vol. 5, no. 9, (2011), pp. 535-538

[9] M. Meier, U. Paetzold, M. Prömpers, T. Merdzhanova, R. Carius, and A. Gordijn: Progress in Photovoltaics: Research and Applications, (2013)

[10] A. Hongsingthong, H. Wada, Y. Moriya, P. Sichanugrist, and M. Konagai: Japanese Journal of Applied Physics, vol. 51, (2012), pp. 2-6

[11] E. Bunte, W. Zhang, and J. Hüpkes: Journal of Vacuum Science \& Technology A: Vacuum, Surfaces, and Films, vol. 28, no. 5, (2010), p. 1255

[12] C. Haase and H. Stiebig: Applied Physics Letters, vol. 91, no. 6, (2007), p. 061116

[13] U. W. Paetzold, E. Moulin, D. Michaelis, W. Böttler, C. Wächter, V. Hagemann, M. Meier, R. Carius, and U. Rau: Applied Physics Letters, vol. 99, no. 18, (2011), p. 181105

[14] C. Battaglia, C.-M. Hsu, K. Söderström, J. Escarré, F.-J. Haug, M. Charrière, M. Boccard, M. Despeisse, D. T. L. Alexander, M. Cantoni, Y. Cui, and C. Ballif: ACS nano, vol. 6, no. 3, (2012), pp. 2790-7

[15] M. Sämann and M. B. Schubert: physica status solidi (RRL) - Rapid Research Letters, vol. 5, no. 10-11, (2011), pp. 379-381

[16] S. Eckhardt, T. Roch, C. Sachse, and A. F. Lasagni: Advanced Engineering Materials, (2013), p. 1-7

[17] L. Li, W. Guo, Z. B. Wang, Z. Liu, D. Whitehead, and B. Luk'yanchuk: Journal of Micromechanics and Microengineering, vol. 19, no. 5, (2009), pp. 054002

[18] K. Piglmayer, R. Denk, and D. Bäuerle: Applied Physics Letters, vol. 80, no. 25, (2002), p. 4693

[19] R. Denk, K. Piglmayer, and D. Bäuerle: Applied Physics A: Materials Science \& Processing, vol. 76, no. 1, (2003), pp. 1-3

[20] M. Birnbaum: Journal of Applied Physics, vol. 36, no. $11,(1965)$, p. 3688

[21] J. E. Sipe, J. F. Young, and J. S. Preston: Physical Review B, vol. 27, no. 2, (1983), pp. 1141-1154
[22] J. F. Young, J. S. Preston, H. M. Van Driel, and J. E. Sipe: Physical Review B, vol. 27, no. 2, (1983), pp. 155-1172

[23] H. van Driel, J. Sipe, and J. Young: Physical Review Letters, vol. 49, no. 26, (1982), pp. 1955-1958

[24] J. Bonse, A. Rosenfeld, and J. Krüger: Journal of Applied Physics, vol. 106, no. 10, (2009), p. 104910

[25] D. Dufft, A. Rosenfeld, S. K. Das, R. Grunwald, and J. Bonse: Journal of Applied Physics, vol. 105, no. 3, (2009), p. 034908

[26] M. Huang, F. Zhao, Y. Cheng, N. Xu, and Z. Xu: Optics express, vol. 16, no. 23, (2008), pp. 19354-65

[27] M. Huang, F. L. Zhao, T. Q. Jia, Y. Cheng, N. S. Xu, and Z. Z. Xu: Nanotechnology, vol. 18, no. 50, (2007), p. 505301

[28] M. Zamfirescu, A. Dinescu, M. Danila, G. Socol, and C. Radu: Applied Surface Science, vol. 258, no. 23, (2012), pp. 9385-9388

[29] J. Huang, S. Beckemper, A. Gillner, and K. Wang: Journal of Micromechanics and Microengineering, vol. 20, no. 9, (2010), p. 095004

[30] S. Ku, S. Haas, G. Schoepe, B. E. Pieters, Q. Ye, and U. Rau: Journal of Optoelectronics and Advanced Materials, vol. 12, no. 3, (2010), pp. 616-620

[31] J. M. Liu: Optics letters, vol. 7, no. 5, (1982), pp. 196-8

[32] J. L. Stay, G. M. Burrow, and T. K. Gaylord: The Review of scientific instruments, vol. 82, no. 2, (2011), p. 023115

[33] F. Burmeister, W. Badowsky, T. Braun, S. Wieprich, J. Boneberg, and P. Leiderer: Applied Surface Science, vol. 144-145, (1999), pp. 461-466

[34] J. L. Stay and T. K. Gaylord: Applied optics, vol. 47, no. 18, (2008), pp. 3221-30

[35] P.Lechner, R. Geyer, H. Schade, B. Rech, O. Kluth, H. Stiebig, Proceedings of the 19th EUPVSEC, (2004), p. 1591

[36] V. Jovanov, X. Xu, S. Shrestha, M. Schulte, J. Hüpkes, M. Zeman, and D. Knipp: Sol. Energy Mater. Sol. Cells, vol. 112, (2013), pp. 182-189

[37] M. Python, O. Madani, D. Dominé, F. Meillaud, E. Vallat-Sauvain, and C. Ballif: Sol. Energy Mater. Sol. Cells, vol. 93, no. 10, (2009), pp. 1714-1720

[38] M. Despeisse, C. Battaglia, M. Boccard, G. Bugnon, M. Charrière, P. Cuony, S. Hänni, L. Löfgren, F. Meillaud, G. Parascandolo, T. Söderström, and C. Ballif: Phys. status solidi, vol. 208, no. 8, (2011), pp. 18631868

(Received: August 22, 2013, Accepted: November 17, 2013) 